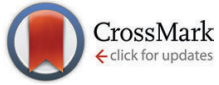

Cite this: Phys. Chem. Chem. Phys., 2014, 16, 23026

\title{
Car-Parrinello and path integral molecular dynamics study of the intramolecular hydrogen bonds in the crystals of benzoylacetone and dideuterobenzoylacetone $\dagger$
}

\author{
Piotr Durlak* and Zdzisław Latajka
}

\begin{abstract}
The dynamics of the intramolecular short hydrogen bond in the molecular crystal of benzoylacetone and its deuterated analogue are investigated using ab initio molecular dynamics simulations. A study on intramolecular hydrogen bonding in 1-phenyl-1,3-butadione (I) and 1-deuteroxy-2-deutero-1-phenylbut-1-en-3-one (II) crystals has been carried out at $160 \mathrm{~K}$ and $300 \mathrm{~K}$ on the CPMD method level and at $300 \mathrm{~K}$ on the PIMD method level. The analysis of the two-dimensional free-energy landscape of reaction coordinate $\delta$-parameter and $R_{\mathrm{O}} \ldots \mathrm{O}$ distances shows that the hydrogen (deuter) between the two oxygen atoms adopts a slightly asymmetrical position in the single potential well. When the nuclear quantum effects are taken into account, very large delocalization of the bridging proton is observed. These studies indicate that hydrogen bonds in the crystal of benzoylacetone have characteristic properties for the type of bonding model resonance-assisted hydrogen bonds (RAHB) without existing the equilibrium of the two tautomers. The infrared spectrum has been calculated, and a comparative vibrational analysis has been performed. The CPMD vibrational results appear to qualitatively agree with the experimental ones.
\end{abstract}

Received 10th June 2014 Accepted 30th August 2014 DOI: $10.1039 /$ c4cp02569e

www.rsc.org/pccp phenomena were observed. These effects are explained by Gilli and Gilli ${ }^{11-16}$ and coworkers who described and named the new class of hydrogen bonds in the series of $\beta$-diketones. This name, resonance-assisted hydrogen bond (RAHB), operates in the scientific environment, and is used when we talk about strong or very strong hydrogen bonds with a neutral donor and acceptor, which are connected by $\pi$-conjugated double bonds. Because $\beta$-diketones are important reagents in organic synthesis and have very interesting properties, they have been recently the subject of many experimental and theoretical studies. ${ }^{17-22}$ Special attention has been paid to the keto-enol tautomerism of the $\beta$-diketones, the structural properties of both keto and enol forms and the nature of the strong $\mathrm{O}-\mathrm{H} \cdots \mathrm{O}$ hydrogen bond in the enol form. ${ }^{23}$

Currently, in the literature debate continues regarding the shape of the potential well for the $\beta$-diketones, especially in the context of the occurrence of the enol forms of $\beta$-diketones and the related intramolecular enol-enol forms. In this regard, the scientific community is divided into two groups. Some researchers report a well with a single minimum ${ }^{24-26}$ and others claim that it is a well with a double minimum function..$^{27,28}$ In addition, large differences in the shape of the free energy function have been observed for the same substances present in different states of matter. ${ }^{23-25,29}$ Previous theoretical studies mainly on the DFT level on the benzoylacetone molecule in vacuum found the potential for proton transfer to be a double minimum with a barrier height 
of $c a .2 \mathrm{kcal} \mathrm{mol}^{-1} \cdot{ }^{23,30}$ After the addition the correction of the zero-point vibrational energy to the total potential energy, the internal barrier vanished and effective potential for the proton motion is a single one. ${ }^{30}$

In the present article, we have described the structures, proton motion, two-dimensional free-energy landscapes and the shapes of the $\mathrm{O}-\mathrm{H} \cdots \mathrm{O}$ potential function in benzoylacetone (BA) (I) and dideuterobenzoylacetone (II) $\left(\mathrm{D}_{2} \mathrm{BA}\right)$ in the solid state. Neutron diffraction data shows that in the solid state the enol structure of benzoylacetone with an almost symmetrical enol ring has been found. ${ }^{24,25}$ We have also discussed the influence of isotope effect on the shape of the free-energy function by analyzing the results of deuterium substitution obtained from MD simulations. To perform these tasks we used the PIMD method, ${ }^{31,32}$ which takes into account the quantum nature of the proton and enables the thorough description of the movement of proton tunneling over the potential barrier.

\section{Computational details}

\subsection{Static calculations}

To localize the key stationary points on the potential energy surface (PES) of the 1-phenyl-1,3-butadione (benzoylacetone) (I) in the solid state, a series of full geometry and cell optimizations with the London-type empirical correction for dispersion interactions, as proposed by Grimme, ${ }^{33}$ together with the vibrational harmonic frequency calculations were undertaken. For the crystal, the structural data was obtained from the neutron diffraction study by Madsen and co-workers. ${ }^{24,25}$ Calculations were performed using the CRYSTAL09 program $^{34,35}$ utilizing the DFT method with PBE functional ${ }^{36}$ with the two shrinking factors $(7,7)$ to generate a commensurate grid of $k$-points in reciprocal space, following the Monkhorst-Pack method. ${ }^{37}$ Calculations were carried out with the consistent Gaussian basis sets of triple-zeta valence with polarization quality for solid-state calculations (pob_TZVP_2012), as proposed by Peintinger, Vilela Oliveira, and Bredow. ${ }^{38}$ For both the crystals, 1-phenyl-1,3butadione (benzoylacetone) (I) (BA) and 1-deuteroxy-2-deutero-1phenylbut-1-en-3-one (dideuterobenzoylacetone) (II) ( $\left.\mathrm{D}_{2} \mathrm{BA}\right)$, calculation of vibrational frequencies in CRYSTAL09 was performed at the $\Gamma$-point. ${ }^{34,35}$

\subsection{Dynamic and quantum dynamic simulations}

Molecular dynamics calculations were carried out using the CPMD program, version 3.15.3. ${ }^{39}$ The initial molecular configuration for the 1-phenyl-1,3-butadione and 1-deuteroxy-2-deutero-1-phenylbut1-en-3-one crystals was optimized by the preconditioned conjugate gradient (PCG) method with the London-type empirical correction for dispersion interactions, as proposed by Grimme ${ }^{33}$ along with periodic boundary conditions (PBCs), which was employed for the solid state calculations. In these cases, real space Ewald summation of electrostatic interactions was carried out taking into account 8 cell replicas in each direction. We also generated the Monkhorst-Pack mesh $(3,3,3)$ for calculated $k$-points in reciprocal space in each direction. The crystals data from the neutron diffraction study by Madsen et $a .^{24,25}$ were selected as the starting points. The crystals are monoclinic, benzoylacetone $\left(P 2_{1} / c\right)$ with cell dimensions of $a=8.028, b=5.483$, $c=19.478 \AA$, and $\alpha=\gamma=90^{\circ}, \beta=110.42^{\circ}$ with four formula units in the unit cell $(Z=4)$ and dideuterobenzoylacetone $\left(P 2_{1} / c\right)$ with cell dimensions $a=8.015, b=5.485, c=19.462 \AA$, and $\alpha=\gamma=90^{\circ}, \beta=110.34^{\circ}$ with four formula units in the unit cell $(Z=4)$. Molecular dynamics (NVT ensemble) were carried out at $160 \mathrm{~K}$ and $300 \mathrm{~K}$, respectively, with a time step of 3.0 a.u. $(0.072566 \mathrm{fs})$ coupled to a Nosé-Hoover chains thermostat ${ }^{40}$ at a frequency of $3200 \mathrm{~cm}^{-1}$. The experimental values of unit cell parameters were used in the CPMD and PIMD simulations. An electronic mass parameter of 600 a.u. was employed. Electronic exchange and correlation have been modeled using the gradient-corrected functional of Perdew, Burke and Ernzerhof $(\mathrm{PBE}){ }^{36}$ Core electrons were treated using the norm-conserving atomic pseudopotentials (PP) of Troullier and Martins, ${ }^{41}$ while valence electrons were represented in a

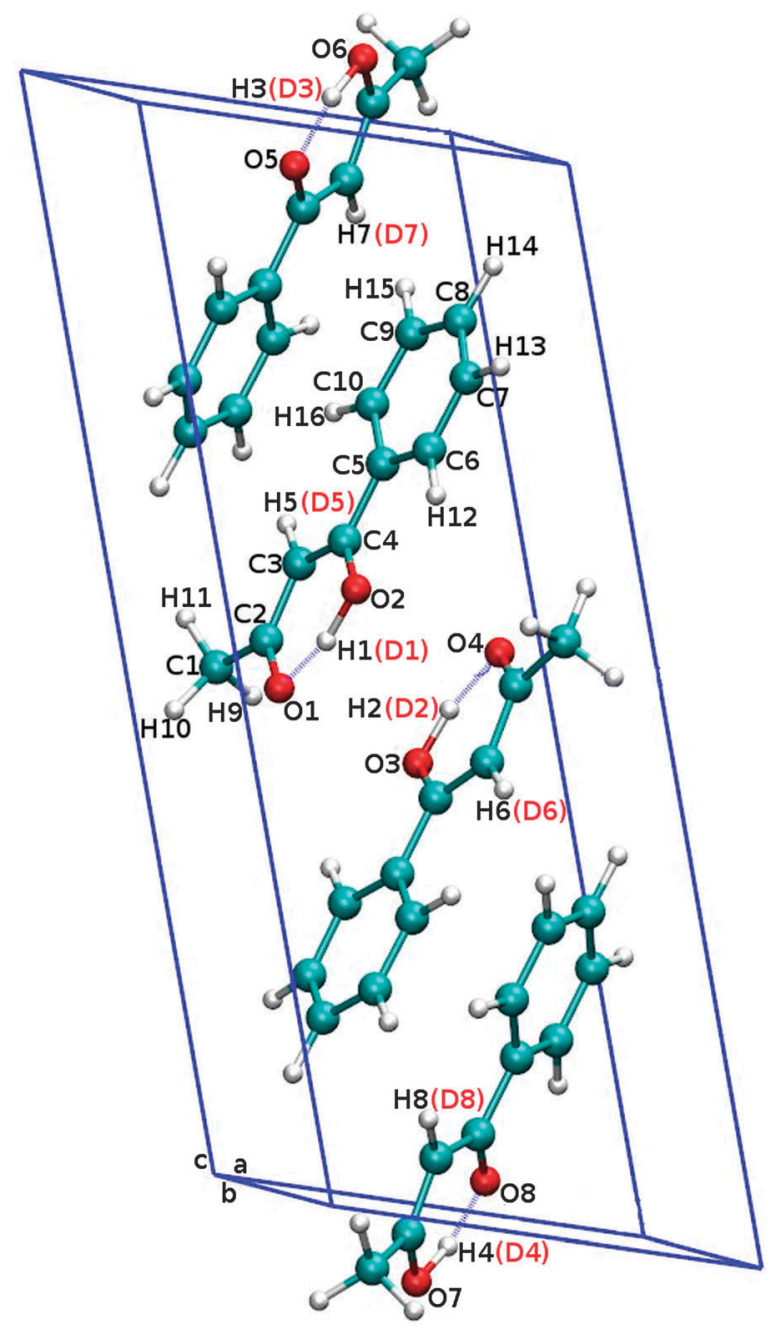

Fig. 1 Unit cell and atoms labeling of 1-phenyl-1,3-butadione (benzoylacetone) crystal. The red colored labels are for dideuterobenzoylacetone crystal. 
plane-wave basis set truncated at an extended energy cut-off of 80 Ry. Following the initial equilibration period (about $8 \mathrm{ps}$ ), data was accrued for further 55 ps for crystals (I) and (II) Car-Parrinello at two different levels of temperature and for both crystals imaginary-time (55 ps) for the path integral dynamics simulation, carried out only at $300 \mathrm{~K}$, respectively for eight (PI8) Trotter replicas (polymer-beads) using the normal mode variable transformation. The data was visualized using the $\mathrm{VMD}^{42}$ and Gnuplot ${ }^{43}$ programs with the path integral data first processed using a script by Kohlmeyer to calculate the centroid position of each set of polymer-beads. ${ }^{44}$

The vibrational spectrum was also calculated using the Fourier transformation of the dipole autocorrelation function obtained from dipole trajectories generated by the CPMD simulation facilitated by the scripts of Forbert and Kohlmeyer. ${ }^{45}$ It is important to point out that this approach includes anharmonic effects and all the vibrational modes for molecules in crystals. The lattice vibrations were not received because fixed experimental values of unit cell were used.

\section{Results and discussion}

\subsection{Structure analysis}

The molecular geometry (in the unit cell) and atoms labeling of 1-phenyl-1,3-butadione (benzoylacetone, BA) in the solid state and its deuterated analogue are shown in Fig. 1. Red labeling was used for the second structure when two hydrogen atoms (H1, H5) in a single molecule has been substituted by deuterium. In Table 1, the calculated selected interatomic distances and angles after optimization compared with the average geometrical parameters from CPMD (standard deviation in brackets) and with the existing experimental data for both the crystals are presented. As can be inferred from Table 1, distances between heavy atoms in the hydrogen bond (O1-O2) in the studied crystals are very short ( $c a .2 .5 \AA)$ and have a similar length regardless of the method of analysis. We can also observe that the average lengths of the deuterated bridge in the analogue (II) are slightly longer than the average lengths of the H-bridge of the structure (I). It shows very good agreement of computed MD

Table 1 Calculated selected geometrical parameters after optimization compared with the average geometrical parameters from CPMD (standard deviation in brackets) and the existing experimental data for benzoylacetone (I) and dideuterobenzoylacetone (II) crystals (bond lengths and unit cell parameters are in $\AA$, angles and dihedrals are in degrees)

\begin{tabular}{|c|c|c|c|c|c|c|c|c|}
\hline \multirow[b]{3}{*}{ Parameter } & \multirow{3}{*}{$\begin{array}{l}\text { PBE/ } \\
\text { pob_TZVP_2012 }\end{array}$} & \multirow{3}{*}{$\begin{array}{l}\text { PBE/PCG/ } \\
80 \mathrm{Ry}\end{array}$} & \multicolumn{4}{|l|}{ CPMD avg. } & \multirow{2}{*}{\multicolumn{2}{|c|}{ Exptl. $^{24-26}$}} \\
\hline & & & \multicolumn{2}{|l|}{$80 \mathrm{Ry} / 160 \mathrm{~K}$} & \multicolumn{2}{|l|}{$80 \mathrm{Ry} / 300 \mathrm{~K}$} & & \\
\hline & & & I & II & I & II & I & II \\
\hline $\mathrm{O} 1-\mathrm{O} 2$ & 2.451 & 2.427 & $2.493(0.071)$ & $2.498(0.069)$ & $2.511(0.103)$ & $2.515(0.100)$ & 2.502 & 2.522 \\
\hline $\mathrm{O} 2-\mathrm{H} 1 / \mathrm{O} 2-\mathrm{D} 1$ & 1.069 & 1.073 & $1.164(0.195)$ & $1.161(0.198)$ & $1.225(0.233)$ & $1.205(0.234)$ & 1.245 & 1.002 \\
\hline $\mathrm{H} 1 \cdots \mathrm{O} 1 / \mathrm{D} 1 \cdots \mathrm{O} 1$ & 1.450 & 1.405 & $1.404(0.220)$ & $1.416(0.224)$ & $1.372(0.277)$ & $1.397(0.269)$ & 1.329 & 1.611 \\
\hline $\mathrm{O} 1-\mathrm{C} 2$ & 1.286 & 1.277 & $1.286(0.029)$ & $1.285(0.029)$ & $1.290(0.365)$ & $1.290(0.036)$ & 1.286 & 1.290 \\
\hline $\mathrm{O} 2-\mathrm{C} 4$ & 1.336 & 1.324 & $1.319(0.029)$ & $1.319(0.029)$ & $1.316(0.037)$ & $1.316(0.037)$ & 1.293 & 1.293 \\
\hline C2-C3 & 1.418 & 1.426 & $1.416(0.028)$ & $1.416(0.028)$ & $1.415(0.035)$ & $1.415(0.036)$ & 1.414 & 1.403 \\
\hline C4-C3 & 1.388 & 1.392 & $1.400(0.026)$ & $1.399(0.027)$ & $1.406(0.034)$ & $1.406(0.034)$ & 1.405 & 1.403 \\
\hline C2-C1 & 1.494 & 1.492 & $1.500(0.024)$ & $1.501(0.025)$ & $1.503(0.033)$ & $1.503(0.033)$ & 1.499 & 1.493 \\
\hline C4-C5 & 1.462 & 1.473 & $1.475(0.023)$ & $1.474(0.023)$ & $1.477(0.032)$ & $1.477(0.031)$ & 1.483 & 1.482 \\
\hline C5-C6 & 1.408 & 1.402 & $1.409(0.020)$ & $1.409(0.019)$ & $1.411(0.027)$ & $1.411(0.028)$ & 1.406 & \\
\hline C6-C7 & 1.389 & 1.394 & $1.397(0.019)$ & $1.396(0.019)$ & $1.398(0.026)$ & $1.403(0.026)$ & 1.402 & \\
\hline $\mathrm{C} 7-\mathrm{C} 8$ & 1.395 & 1.397 & $1.395(0.019)$ & $1.395(0.019)$ & $1.396(0.026)$ & $1.396(0.026)$ & 1.387 & \\
\hline C8-C9 & 1.395 & 1.390 & $1.397(0.019)$ & $1.397(0.018)$ & $1.398(0.026)$ & $1.399(0.026)$ & 1.404 & \\
\hline C9-C10 & 1.389 & 1.396 & $1.396(0.019)$ & $1.395(0.018)$ & $1.397(0.026)$ & $1.397(0.026)$ & 1.394 & \\
\hline C10-C5 & 1.403 & 1.406 & $1.402(0.019)$ & $1.402(0.019)$ & $1.403(0.027)$ & $1.403(0.026)$ & 1.404 & \\
\hline C3-H5/C3-D5 & 1.084 & 1.081 & $1.083(0.021)$ & $1.084(0.020)$ & $1.085(0.028)$ & $1.085(0.028)$ & 1.076 & \\
\hline C1-H9 & 1.099 & 1.102 & $1.101(0.022)$ & $1.100(0.022)$ & $1.103(0.031)$ & $1.103(0.030)$ & 1.064 & \\
\hline C1-H10 & 1.096 & 1.093 & $1.101(0.022)$ & $1.101(0.023)$ & $1.102(0.031)$ & $1.102(0.030)$ & 1.062 & \\
\hline C1-H11 & 1.094 & 1.091 & $1.100(0.022)$ & $1.100(0.022)$ & $1.103(0.031)$ & $1.103(0.030)$ & 1.051 & \\
\hline C6-H12 & 1.091 & 1.089 & $1.086(0.021)$ & $1.085(0.020)$ & $1.087(0.028)$ & $1.087(0.028)$ & 1.079 & \\
\hline C7-H13 & 1.089 & 1.085 & $1.090(0.021)$ & $1.091(0.022)$ & $1.093(0.030)$ & $1.092(0.029)$ & 1.090 & \\
\hline C8-H14 & 1.090 & 1.088 & $1.093(0.022)$ & $1.093(0.021)$ & $1.094(0.029)$ & $1.094(0.029)$ & 1.091 & \\
\hline C9-H15 & 1.088 & 1.087 & $1.083(0.021)$ & $1.085(0.020)$ & $1.087(0.028)$ & $1.087(0.028)$ & 1.090 & \\
\hline C10-H16 & 1.088 & 1.085 & $1.086(0.022)$ & $1.086(0.022)$ & $1.088(0.029)$ & $1.088(0.029)$ & 1.085 & \\
\hline$<\mathrm{O} 1-\mathrm{H} 1-\mathrm{O} 2 /<\mathrm{O} 1-\mathrm{D} 1-\mathrm{O} 2$ & 153.07 & 156.67 & $152.03(4.91)$ & $154.49(4.87)$ & $150.76(6.89)$ & $150.53(6.90)$ & 152.36 & 148.84 \\
\hline$<\mathrm{H} 1-\mathrm{O} 2-\mathrm{C} 4 /<\mathrm{D} 1-\mathrm{O} 2-\mathrm{C} 4$ & 104.89 & 103.12 & $103.88(3.07)$ & $104.14(3.05)$ & $103.71(4.15)$ & $103.83(4.10)$ & 103.24 & 108.73 \\
\hline$<\mathrm{H} 1-\mathrm{O} 1-\mathrm{C} 2 /<\mathrm{D} 1-\mathrm{O} 1-\mathrm{C} 2$ & 100.72 & 100.25 & $100.87(3.11)$ & $100.83(3.09)$ & $101.07(4.10)$ & $101.00(4.10)$ & 101.24 & 106.73 \\
\hline$<\mathrm{O} 2-\mathrm{C} 4-\mathrm{C} 3$ & 119.44 & 119.74 & $119.98(1.98)$ & $120.02(1.95)$ & $120.02(2.69)$ & $120.05(2.71)$ & 120.93 & 121.21 \\
\hline$<\mathrm{O} 1-\mathrm{C} 2-\mathrm{C} 3$ & 121.29 & 120.87 & $121.49(2.05)$ & $121.58(2.03)$ & $121.51(2.74)$ & $121.57(2.78)$ & 122.13 & 122.4 \\
\hline$<\mathrm{C} 4-\mathrm{C} 3-\mathrm{C} 2$ & 120.09 & 119.20 & $120.29(2.05)$ & $120.39(2.03)$ & $120.45(2.78)$ & $120.55(2.81)$ & 120.93 & 120.3 \\
\hline$<\mathrm{C} 4-\mathrm{C} 3-\mathrm{H} 5 /<\mathrm{C} 4-\mathrm{C} 3-\mathrm{D} 5$ & 120.69 & 121.36 & $120.30(3.06)$ & $120.25(3.01)$ & $120.05(4.19)$ & $120.10(4.07)$ & 121.54 & \\
\hline$<\mathrm{C} 2-\mathrm{C} 3-\mathrm{H} 5 /<\mathrm{C} 2-\mathrm{C} 3-\mathrm{D} 5$ & 119.01 & 119.42 & $118.93(2.98)$ & $118.88(2.99)$ & $118.66(4.13)$ & $118.55(4.02)$ & 118.74 & \\
\hline$<\mathrm{O} 1-\mathrm{C} 2-\mathrm{C} 1$ & 118.27 & 118.15 & $118.26(2.83)$ & $118.38(2.83)$ & $117.92(3.64)$ & $117.89(3.75)$ & 117.03 & 116.8 \\
\hline$<\mathrm{C} 2-\mathrm{C} 1-\mathrm{H} 9$ & 108.12 & 110.16 & $110.21(3.46)$ & $109.96(3.49)$ & $110.26(4.76)$ & $110.12(4.68)$ & 109.84 & \\
\hline$<\mathrm{C} 2-\mathrm{C} 1-\mathrm{H} 10$ & 108.83 & 108.79 & $109.73(3.93)$ & $110.37(3.59)$ & $110.09(4.64)$ & $110.27(4.65)$ & 110.84 & \\
\hline$<\mathrm{C} 2-\mathrm{C} 1-\mathrm{H} 11$ & 111.72 & 111.66 & $110.82(3.53)$ & $110.42(3.53)$ & $110.36(4.72)$ & $110.46(4.68)$ & 112.65 & \\
\hline$<\mathrm{C} 1-\mathrm{C} 2-\mathrm{C} 3$ & 120.43 & 120.98 & $120.09(3.03)$ & $119.88(2.98)$ & $120.28(3.94)$ & $120.23(3.93)$ & 120.92 & 120.8 \\
\hline
\end{tabular}




\begin{tabular}{|c|c|c|c|c|c|c|c|c|}
\hline \multirow[b]{3}{*}{ Parameter } & \multirow{3}{*}{$\begin{array}{l}\text { PBE/ } \\
\text { pob_TZVP_2012 }\end{array}$} & \multirow{3}{*}{$\begin{array}{l}\text { PBE/PCG/ } \\
80 \mathrm{Ry}\end{array}$} & \multicolumn{4}{|l|}{ CPMD avg. } & \multirow{2}{*}{\multicolumn{2}{|c|}{ Exptl. $^{24-26}$}} \\
\hline & & & \multicolumn{2}{|l|}{$80 \mathrm{Ry} / 160 \mathrm{~K}$} & \multicolumn{2}{|l|}{$80 \mathrm{Ry} / 300 \mathrm{~K}$} & & \\
\hline & & & I & II & I & II & I & II \\
\hline$<\mathrm{O} 2-\mathrm{C} 4-\mathrm{C} 5$ & 115.65 & 115.23 & $116.93(2.52)$ & $116.99(2.59)$ & $117.25(3.21)$ & $117.11(3.30)$ & 116.43 & 116.01 \\
\hline$<$ C4-C5-C6 & 119.93 & 118.87 & $119.87(2.26)$ & $119.95(2.23)$ & $122.42(3.28)$ & $119.95(3.01)$ & 121.52 & \\
\hline$<$ C4-C5-C10 & 120.87 & 121.88 & $121.34(2.21)$ & $121.31(2.19)$ & $121.32(2.98)$ & $121.30(2.93)$ & 119.02 & \\
\hline$<\mathrm{C} 6-\mathrm{C} 7-\mathrm{C} 8$ & 120.09 & 119.91 & $120.37(1.87)$ & $120.41(1.90)$ & $120.40(2.56)$ & $120.39(2.57)$ & 120.43 & \\
\hline$<$ C10-C9-C8 & 120.53 & 120.40 & $120.10(1.84)$ & $120.04(1.88)$ & $120.02(2.54)$ & $119.95(2.52)$ & 119.93 & \\
\hline$<\mathrm{C} 7-\mathrm{C} 8-\mathrm{C} 9$ & 119.82 & 119.98 & 119.49 (1.87) & 119.49 (1.85) & $119.33(2.52)$ & $119.38(2.54)$ & 120.13 & \\
\hline <C8-C9-C10 & 120.53 & 120.40 & $120.10(1.84)$ & 119.49 & $119.33(2.53)$ & $119.95(2.52)$ & 119.93 & \\
\hline$<\mathrm{C} 5-\mathrm{C} 10-\mathrm{H} 16$ & 120.79 & 121.06 & $120.18(2.85)$ & $120.10(2.83)$ & 120.05 (3.69) & $120.08(3.93)$ & 119.14 & \\
\hline <C5-C6-H12 & 119.22 & 119.05 & $119.19(2.96)$ & $119.24(2.94)$ & $119.02(4.07)$ & $119.04(4.08)$ & 120.94 & \\
\hline$<\mathrm{H} 12-\mathrm{C} 6-\mathrm{C} 7$ & 120.45 & 120.53 & $120.28(2.96)$ & $120.25(2.98)$ & $120.23(4.12)$ & 120.25 & 119.24 & \\
\hline$<\mathrm{H} 15-\mathrm{C} 9-\mathrm{C} 8$ & 120.28 & 120.28 & $120.13(2.98)$ & $120.17(2.98)$ & $120.09(4.05)$ & $119.91(4.04)$ & 120.44 & \\
\hline$<\mathrm{C} 7-\mathrm{C} 8-\mathrm{H} 14$ & 118.90 & 120.40 & $120.02(2.95)$ & $120.02(2.90)$ & 119.98 (3.99) & $119.91(4.04)$ & 120.74 & \\
\hline <C9-C8-H14 & 121.27 & 119.59 & $120.22(2.97)$ & $120.24(2.93)$ & $120.23(4.04)$ & $120.24(4.08)$ & 119.24 & \\
\hline$\phi \mathrm{O} 2-\mathrm{C} 4-\mathrm{C} 5-\mathrm{C} 6$ & -174.39 & -176.07 & $-173.74(3.25)$ & $-173.41(3.25)$ & $-173.02(3.87)$ & $-173.43(3.26)$ & -173.54 & -173.72 \\
\hline$\phi \mathrm{H} 9-\mathrm{C} 1-\mathrm{C} 2-\mathrm{O} 1$ & 37.99 & 29.85 & $32.56(4.18)$ & $33.04(4.12)$ & $35.02(4.25)$ & $37.22(4.03)$ & 38.05 & 38.45 \\
\hline$\phi \mathrm{H} 11-\mathrm{C} 1-\mathrm{C} 2-\mathrm{O} 1$ & -80.87 & -88.50 & $-84.06(3.56)$ & $-87.23(3.52)$ & $-83.45(3.78)$ & $-84.02(3.25)$ & -81.06 & -82.07 \\
\hline$a$ & 7.265 & & & & & & 8.028 & 8.015 \\
\hline$b$ & 5.317 & & & & & & 5.483 & 5.485 \\
\hline$c$ & 18.694 & & & & & & 19.478 & 19.462 \\
\hline$\alpha$ & 90.00 & & & & & & 90.00 & 90.00 \\
\hline$\beta$ & 107.24 & & & & & & 110.42 & 110.34 \\
\hline$\gamma$ & 90.00 & & & & & & 90.00 & 90.00 \\
\hline
\end{tabular}

(a)

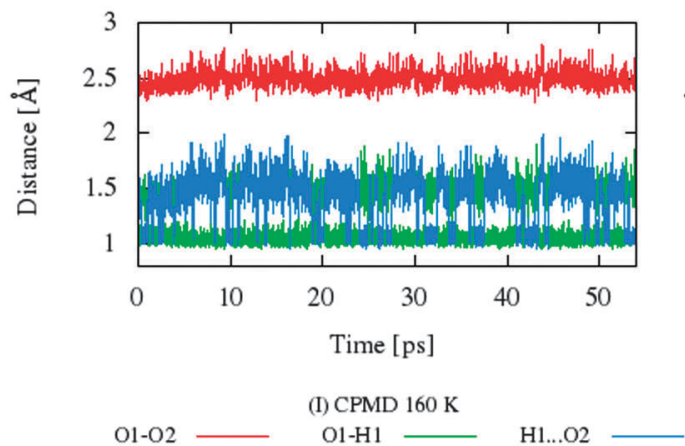

(b)

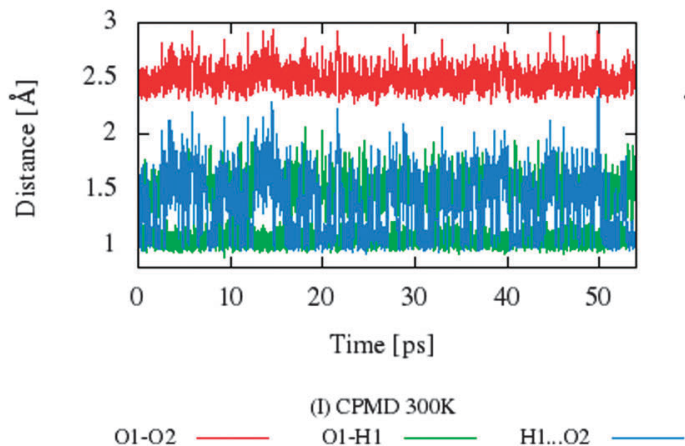

(c)

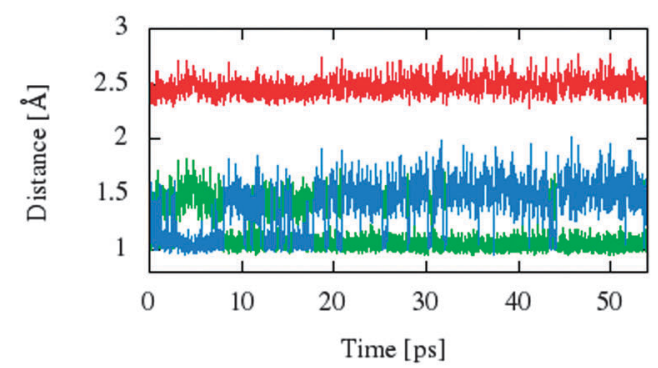

(II) CPMD $160 \mathrm{~K}$

(d)

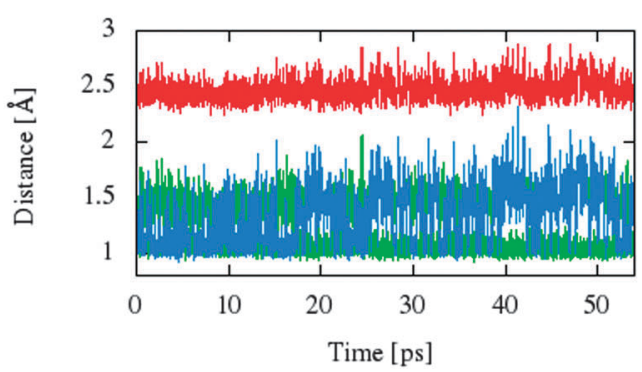

(II) CPMD $300 \mathrm{~K}$

O1-O2 - O1-D1 - D1 ...02

Fig. 2 Time evolution of bonds involved in the hydrogen bonds $\mathrm{O} 1-\mathrm{H} 1(\mathrm{D} 1) \ldots \mathrm{O} 2$ for (a) benzoylacetone at $160 \mathrm{~K}$, (b) benzoylacetone at $300 \mathrm{~K}$ for (c) dideuterobenzoylacetone at $160 \mathrm{~K}$, and for (d) dideuterobenzoylacetone at $300 \mathrm{~K}$ from the CPMD calculations. 
(a)

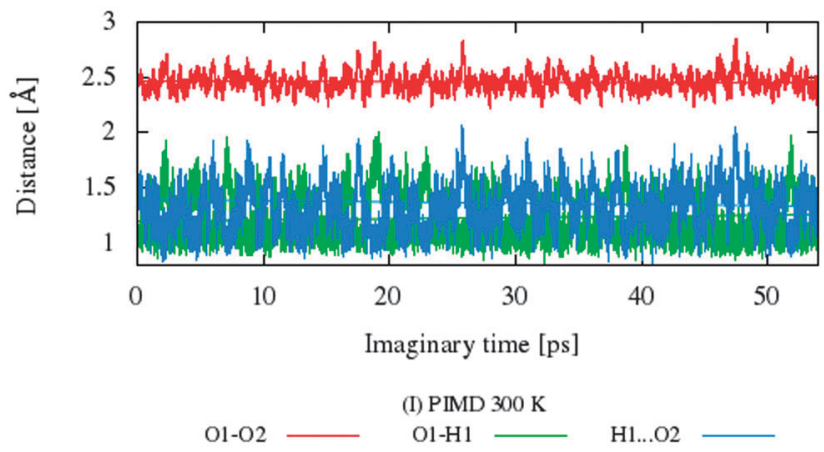

(b)

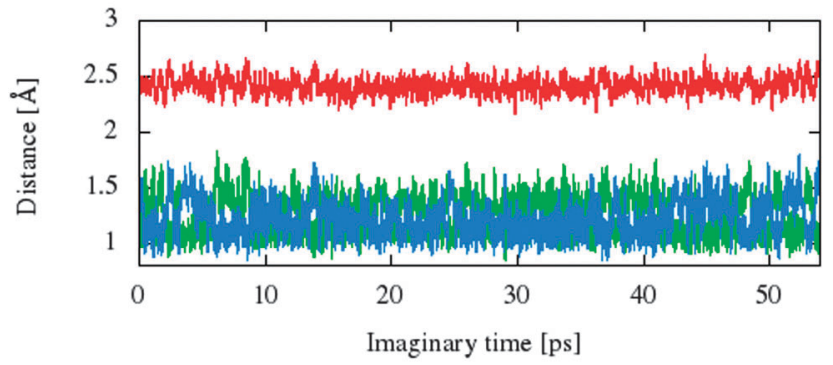

O1-O2 $\quad$ OI-D1 $2-\quad$ D1...02

Fig. 3 Time evolution of bonds involved in the hydrogen bonds $\mathrm{O} 1-\mathrm{H} 1(\mathrm{D} 1) \ldots \mathrm{O} 2$ for (a) benzoylacetone at $300 \mathrm{~K}$ and for (b) dideuterobenzoylacetone at $300 \mathrm{~K}$ from the PIMD calculations.

geometrical parameters with the neutron diffraction experiment. ${ }^{24,25}$ However, the geometry optimization on the static methods level slightly underestimates the length of the hydrogen bridge of about $0.051 \AA$ for the structure (I). For analyzing the geometric structure of the molecule in terms of the prevalence of characteristics model RAHB, we should carefully consider the length of the four bonds in the keto-enol parts of the molecule. Taking into the account our simulations carried out on the static and especially on dynamic levels, we can conclude that the bond lengths $(\mathrm{O} 1=\mathrm{C} 2 / \mathrm{O} 2-\mathrm{C} 4$ and $\mathrm{C} 4=\mathrm{C} 3 / \mathrm{C} 2-\mathrm{C} 3)$ coincide with typical lengths for the bonds determined experimentally. For example, let us analyze the data from both simulations for the crystal (I), static optimization on the DFT method level and molecular dynamics in terms of Car-Parrinello. The resulting values are presented in order $\mathrm{O} 1=\mathrm{C} 2 / \mathrm{O} 2-\mathrm{C} 4(1.286 / 1.336 \AA)$ and $\mathrm{C} 4=\mathrm{C} 3 / \mathrm{C} 2-\mathrm{C} 3(1.388 / 1.418 \AA) ; \mathrm{O} 1=\mathrm{C} 2 / \mathrm{O} 2-\mathrm{C} 4(1.290 / 1.316 \AA)$ and $\mathrm{C} 4=\mathrm{C} 3 / \mathrm{C} 2-\mathrm{C} 3(1.406 / 1.415 \AA)$ for DFT and CPMD methods, respectively. It can be concluded that the equivalence of bond lengths may be attributed to delocalization over a conjugated $\pi$-bonded system in the keto-enol group. ${ }^{15}$ The quoted values of the bonds lengths clearly indicate different chemical bonds character. O2-C4, $\mathrm{C} 2-\mathrm{C} 3$ bonds are single and $\mathrm{O} 1=\mathrm{C} 2$, $\mathrm{C} 4=\mathrm{C} 3$ bonds have a double bond character. In addition, we have a relatively short hydrogen bridge and a non-ideal symmetrical position of the proton. All of these features fit well in the assumptions of the RAHB model proposed by Gilli. ${ }^{15}$ The large non-linearity of the hydrogen bond is noteworthy. Each of the methods of calculation indicates that the angle values of the hydrogen bridge are between 150 and 157 degrees, which are close to the experimental data. ${ }^{24,25}$ Moreover, the computational results are in good agreement with the experimental data of the dihedral angles, as shown in Table 1. In our opinion this confirms the correctness of the implementation of the simulation because (a)

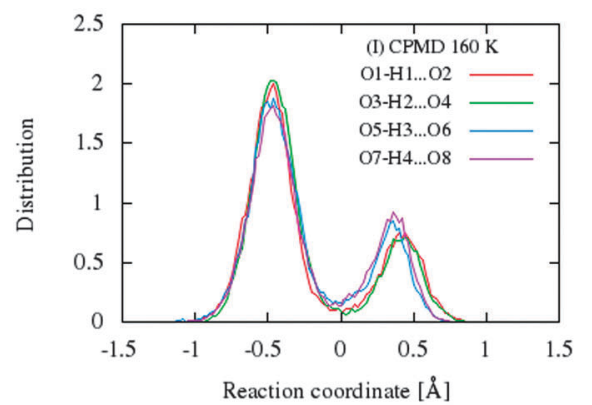

(b)

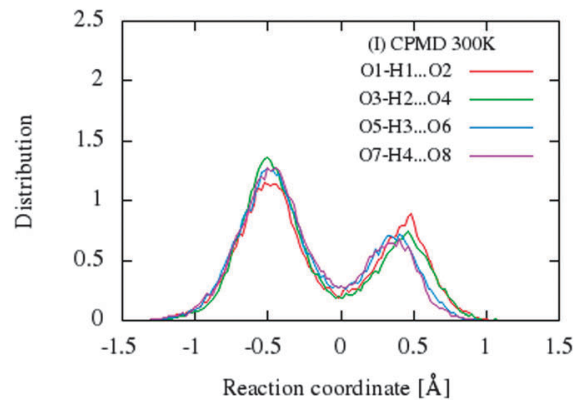

(c)

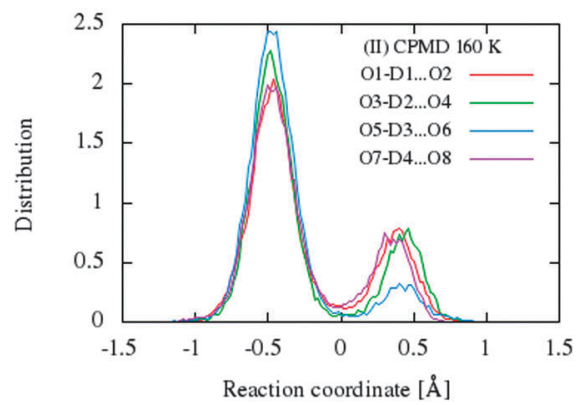

(d)

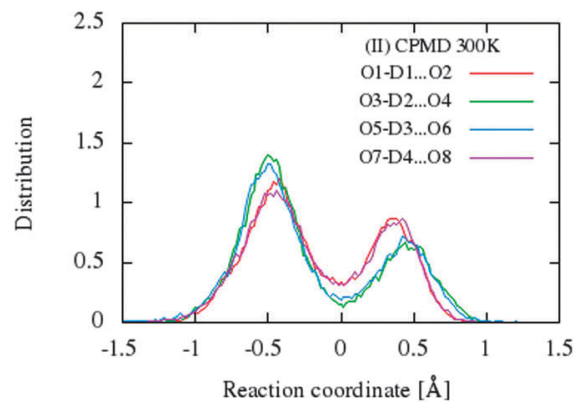

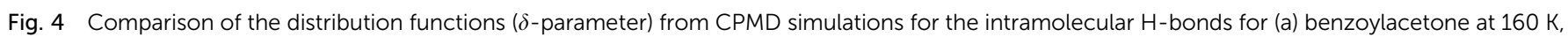
(b) benzoylacetone at $300 \mathrm{~K}$ for (c) dideuterobenzoylacetone at $160 \mathrm{~K}$, and for (d) dideuterobenzoylacetone at $300 \mathrm{~K}$. 
(a)

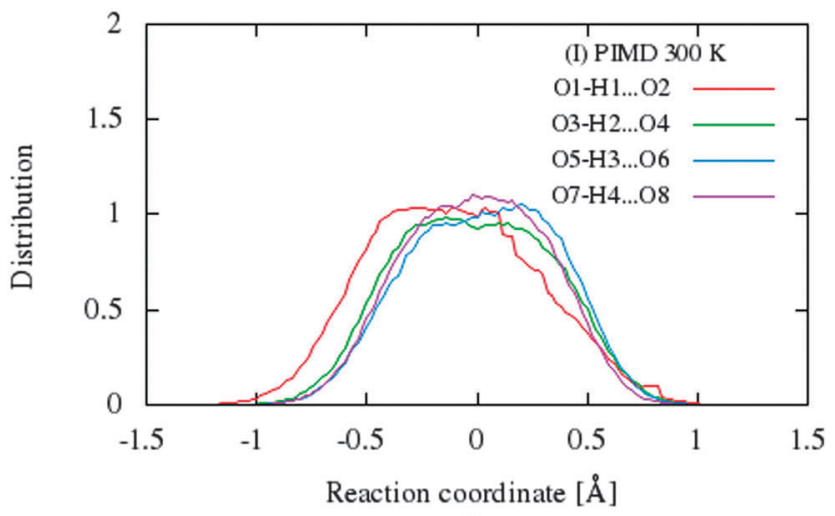

(b)

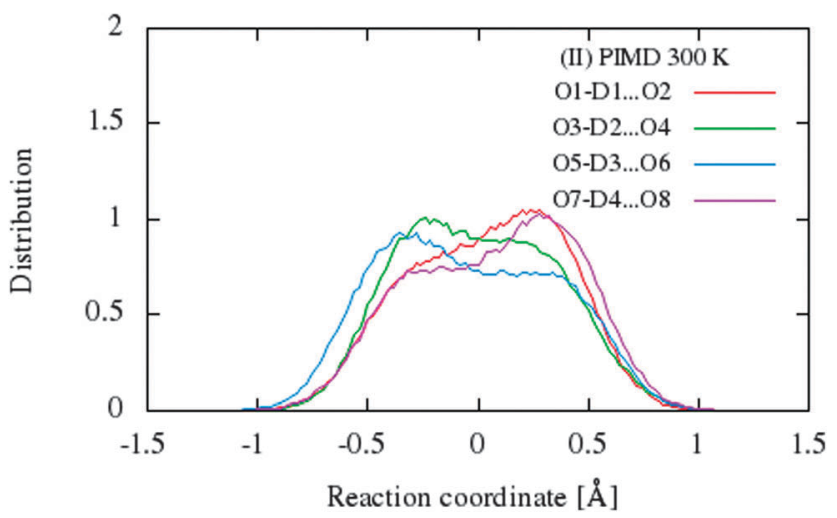

Fig. 5 Comparison of the distribution functions ( $\delta$-parameter) from PIMD simulations for the intramolecular $\mathrm{H}$-bonds for (a) benzoylacetone at $300 \mathrm{~K}$ and (b) dideuterobenzoylacetone at $300 \mathrm{~K}$. these parameters are particularly sensitive to structural errors. ${ }^{46}$ Moreover, the optimized parameters of the unit cell are in reasonable agreement with the experimental values. ${ }^{24,25}$ The largest error (ca. 10\%) is noted for a parameter. For the remaining lattice parameters, errors between optimized and experimental values are smaller than 5\%. This appears to confirm the need to use dispersion corrections to the full energy for calculations on the DFT method level. ${ }^{47}$

\subsection{Molecular dynamics simulations}

The CP dynamic simulations were performed at two different temperatures because the experimental data for crystals are reported in this manner, ${ }^{26}$ while PIMD simulations were conducted only at $300 \mathrm{~K}$ due to a very high computational cost. The time evolution behavior of bond lengths directly involved in the selected intramolecular hydrogen bonds O2-H1(D1) . O 1 from crystals (I) and (II) at $160 \mathrm{~K}$ and $300 \mathrm{~K}$ is presented in Fig. 2. The careful analysis of the strong O2-H1(D1) ‥O1 intramolecular hydrogen bond shows very large fluctuation of the bridging proton/deuter between the two oxygen atoms in crystals (I) and (II) at $160 \mathrm{~K}$ (see Fig. 2a and c) and significantly larger mobility of proton/deuter in hydrogen bridge in the simulations at $300 \mathrm{~K}$ (see Fig. $2 \mathrm{~b}$ and d). As expected, higher temperature of simulation causes more frequent proton/deuter hops (transfer). At $160 \mathrm{~K}$, proton/deuter jumps about 80 times while at $300 \mathrm{~K}$ this occurs almost three times more often. According to our estimates, the full process of proton hopping in the crystal of benzoylacetone takes about $12-16 \mathrm{fs}$, which is close to the experimental and theoretical data. ${ }^{5,6,48,49}$ When we analyze the results of the PIMD simulation taking into account the quantum effects, it can be seen (a)

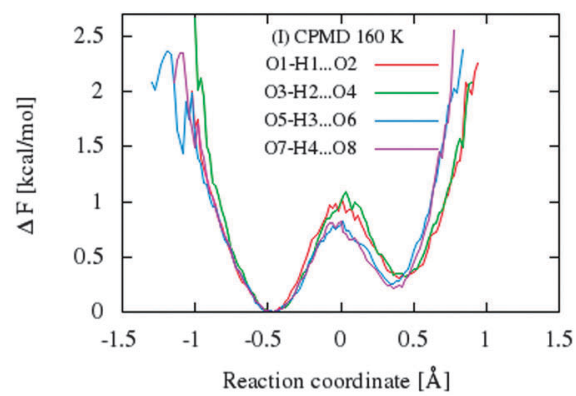

(b)

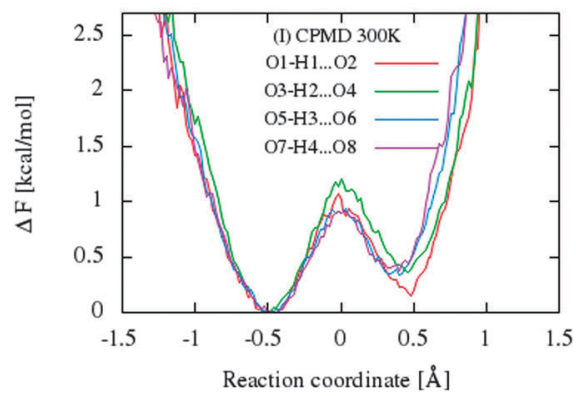

(c)

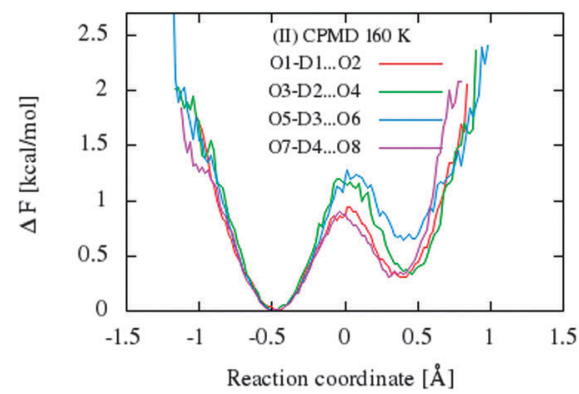

(d)

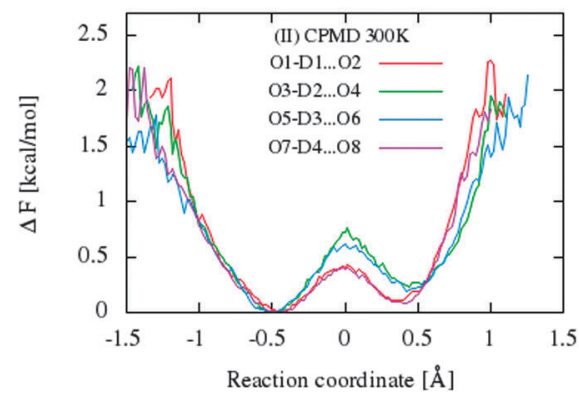

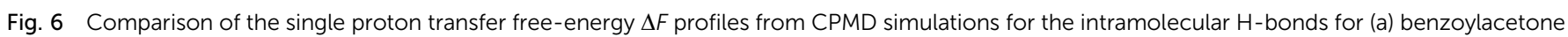
at $160 \mathrm{~K}$, (b) benzoylacetone at $300 \mathrm{for}$ (c) dideuterobenzoylacetone at $160 \mathrm{~K}$, and for (d) dideuterobenzoylacetone at $300 \mathrm{~K}$. 
that the proton/deuter is completely delocalized between the two carbonyl oxygens (see Fig. 3). From the CPMD simulations at $160 \mathrm{~K}$, the O2-H1(D1) bonds length changes in the ranges 0.953$1.895 \AA$ for the crystal (I) and 0.896-2.052 $\AA$ for the crystal (II), while at $300 \mathrm{~K}$ the $\mathrm{O} 2-\mathrm{H} 1$ (D1) bonds length changes in the ranges 0.945-1.887 $\AA$ for the crystal (I) and 0.917-2.108 $\AA$ for the crystal (II). Averaged O2-H1(D1) distances from the molecular dynamics method (see Table 1) are strongly dependent on temperature and their values are 1.164/1.161 $\AA$ and 1.225/1.205 $\AA$ for the crystal (I) and (II) at $160 \mathrm{~K}$ and $300 \mathrm{~K}$, respectively. Following the distance of the hydrogen bridge, we observe that the $\mathrm{O}-\mathrm{H}$ bonds are extremely sensitive to changes in temperatures. This phenomenon has been described by Wilson and co-workers ${ }^{50}$ on the basis of single neutron diffraction studies for the benzoic acid crystal. The analysis of the distribution function of proton/deuter in the hydrogen bridge shows the importance of quantum effects. Their inclusion in the calculation completely changes the picture of physical processes. Fig. 4 and 5 present the distribution functions ( $\delta$-parameter) of proton/deuter position along the reaction coordinate on the basis of our results from the CPMD and PIMD method. To show the influence of quantum effects in a better manner, we have prepared a series of graphs of free energy. Fig. 6 and 7 show the free energy profiles for proton motion obtained from the CPMD and PIMD results. Free energy profiles were calculated following the equation:

$$
\Delta F=-k T \ln [P(\delta)],
$$

where $k$ is the Boltzmann constant, $T$ is the simulation temperature, and $P(\delta)$ is the proton distribution as a function of $\delta$ (the reaction coordinate), which is defined as the difference between the distances $r_{\mathrm{O}-\mathrm{H}(\mathrm{D})}-r_{\mathrm{H}(\mathrm{D})-\mathrm{O}}$ and is a measure of the proton/deuter transfer degree in the hydrogen bond. The value of zero indicated the midpoint of the hydrogen/deuter position in H/D-bond. The profiles of free energy in Fig. 6 demonstrate the absence of an effective barrier for proton transfer even without an inclusion of quantum effects for the CPMD simulation. Calculations show that the quantity of the barrier for proton transfer in the crystal of BA and its deuterated analogue are about $0.25 \mathrm{kcal} \mathrm{mol}^{-1}$ and decreases to about $0.15 \mathrm{kcal} \mathrm{mol}^{-1}$ as temperature increases. This would suggest that during proton transfer we observed the potentials wells with a double minimum; however, when the quantum effects are taken into account, the effective potential shape drastically changes, as shown in Fig. 7a and $\mathrm{b}$. These strong HBs have also been named low-barrier hydrogen bonds (LBHB). ${ }^{51}$ It is interesting to note that the results of CPMD simulations (the double well potential) are very similar to the static DFT calculations of BA molecule in vacuum, ${ }^{23,30}$ whereas the CPMD simulations are in very good agreement with the experimental results showing almost symmetrical H-bond. ${ }^{24,25}$

For a deeper analysis of proton mobility in the studied intramolecular H-bonds, we constructed two-dimensional free-energy landscapes from two-dimensional distribution of $\delta$-parameter and $\mathrm{O} \cdots \mathrm{O}$ distances, as illustrated in Fig. 8, Fig. 1S-3S (in ESI $\dagger$ ), for every hydrogen bridge in the crystal unit, for further analysis for the proton/deuter transfer. As shown in the series of figures from 8 to $3 \mathrm{~S}$ (ESI $\dagger$ ), the panels (a)

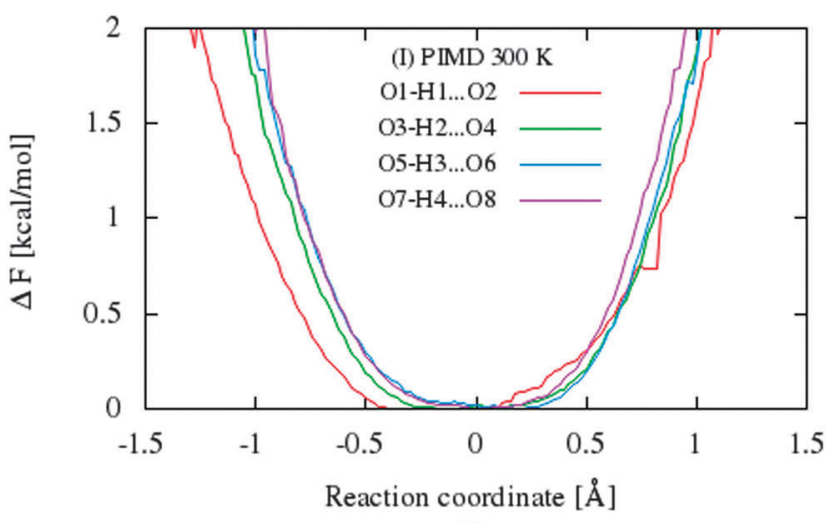

(b)

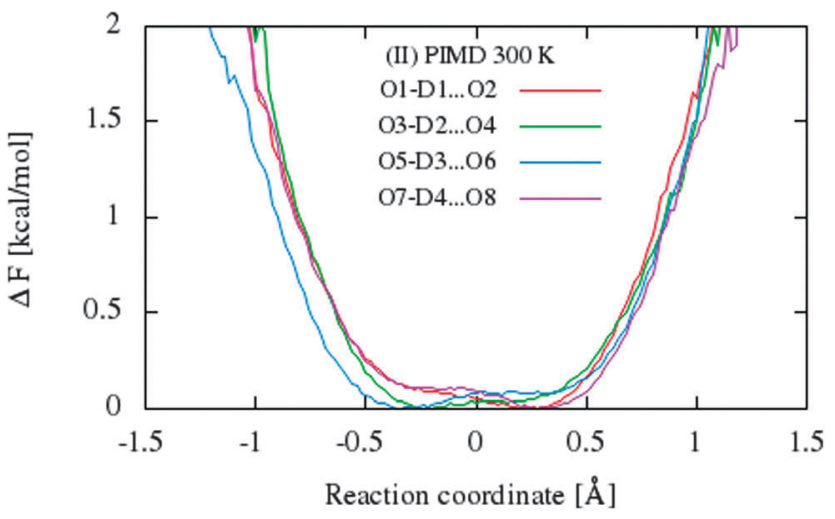

Fig. 7 Comparison of the single proton transfers free-energy $\Delta F$ profiles from PIMD simulations for the intramolecular $\mathrm{H}$-bonds for (a) benzoylacetone at 300 and for (b) dideuterobenzoylacetone at $300 \mathrm{~K}$.

(a) and (b) presented the free energy surfaces obtained for crystal (I) from CPMD simulations and panel (c) from PIMD simulations. Similarly, the sections (d)-(f) of figures were obtained for the second crystal (II).

Let us now briefly discuss the abovementioned landscapes. As shown in sections $a, b, d$ and e of figures, the free energy surfaces obtained from CP simulations have two minima, while sections (c) and (f) obtained from PIMD simulations have one minimum in each case. As shown in Fig. 7a and b, the nuclear quantum effects remove the proton transfer barrier, allowing barrier-less proton transfer. Considering the two-dimensional free-energy landscapes, we can also see a substantial mobility and relocation of proton position at higher temperatures of simulations and negligible impact of isotope effect on the shape and height of the energy barrier of proton/deuter transfer. Moreover, despite the fact that the potential well has one minimum, the position of the proton/deuter is not perfectly symmetrical. It is a very subtle effect, which is often accompanied by typical resonance-assisted hydrogen bond.

According to Gilli and Gilli, ${ }^{15,16}$ for the description resonanceassisted hydrogen bonded systems, the very important so-called $\pi$-delocalization index is defined as:

$$
\Lambda=\frac{1}{2}\left(1-\frac{Q}{0.32}\right)
$$


(a) I $160 \mathrm{~K} \mathrm{CP}$

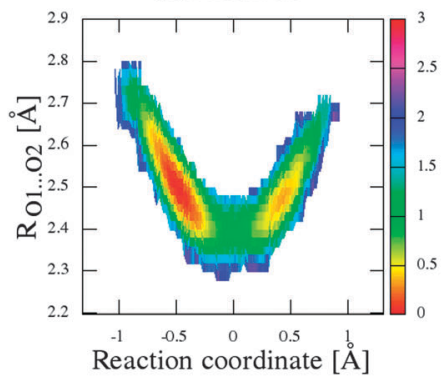

(d) II $160 \mathrm{~K} \mathrm{CP}$

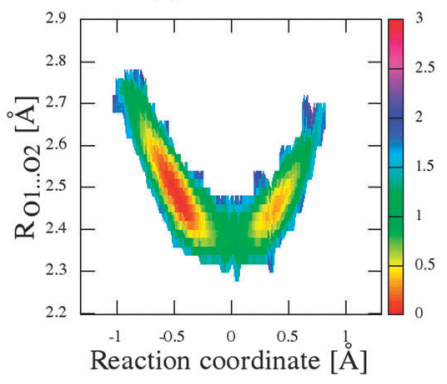

(b) $\mathrm{I} 300 \mathrm{~K} \mathrm{CP}$

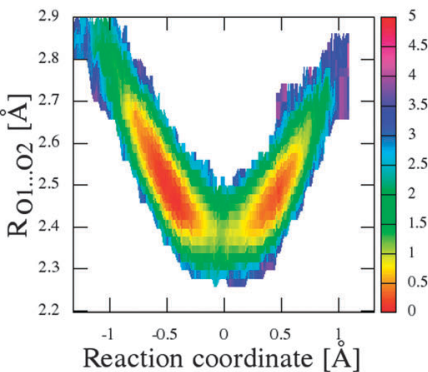

(e) II $300 \mathrm{~K} \mathrm{CP}$

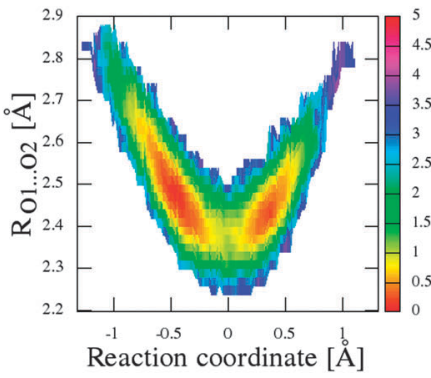

(c) I 300K PI

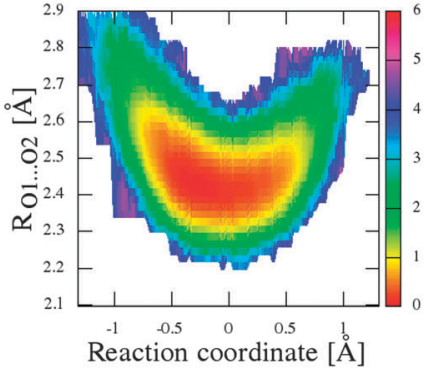

(f) II $300 \mathrm{~K}$ PI

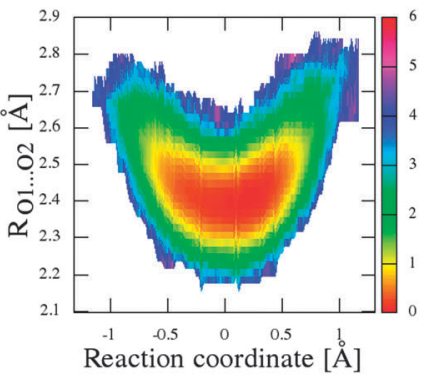

Fig. 8 Two-dimensional free-energy landscape of $\delta$-parameter (reaction coordinate) and $R_{\mathrm{O} 1 \ldots \mathrm{O} 2}$ distances for crystal (I) for (a) CPMD simulation at $160 \mathrm{~K}$, (b) CPMD simulation at $300 \mathrm{~K}$, (c) PIMD simulation at $300 \mathrm{~K}$, and for crystal (II) for (d) CPMD simulation at $160 \mathrm{~K}$, (e) CPMD simulation at $300 \mathrm{~K}$, (f) PIMD simulation at $300 \mathrm{~K}$. The unit of $\Delta F$ free energy (potential of mean force) is $\mathrm{kcal}^{\mathrm{mol}}{ }^{-1}$.

where the $Q=\left(d_{1}-d_{4}\right)+\left(d_{3}-d_{2}\right)$. In our studies, the delocalization parameters $(Q)$ for BA crystal and its deuterated analogue were described by relevant molecular distances $Q=(\mathrm{O} 2-\mathrm{C} 4-\mathrm{O} 1-\mathrm{C} 2)+$ (C2-C3 - C3-C4). According to Gilli and co-workers, ${ }^{15} Q=0$ corresponds to the fully $\pi$-delocalized structure and $Q=-0.32$ or $+0.32 \AA$ corresponds to the completely localized bonding. The $\Lambda$ value of 0.5 indicates a fully delocalized keto-enolic system, whereas $\Lambda$ value closer to 0 or 1 indicates localized bonding. Two-dimensional plots of delocalization parameter $Q$ versus $R_{\mathrm{O} 1 \cdots \mathrm{O} 2}$ distance for crystals (I) and (II) are shown in Fig. 9. Values of $\Lambda$ and $Q$ are calculated on the basis of average bond lengths from CPMD simulation. In both the cases, the 1 -parameter is equal to 0.445 . After a precise analysis of Fig. 9, we can conclude that the intramolecular hydrogen bond in the crystal of BA can be classified as the group of hydrogen bond with RAHB character. In addition, Fig. 9 allows the observation of the correlation between the $Q$ and $A$ parameters and the length of the hydrogen/deuter bridge throughout the course of the simulation. Therefore, according to the classification proposed by Gilli and co-workers, ${ }^{15}$ it can be concluded that changes in the hydrogen and other bonds coupled with the molecular system are characterized by the type of strong $\pi$-delocalized structure (enol-enol forms). However, it should be noted that in this disordered molecular system there are two forms with slightly more contribution from the $\pi$-localized enol-keto (EK) form than $\pi$-localized keto-enol (KE) form. We expect that these mainly result from a little asymmetrical position of the proton/ deuter in the bridge.

The calculated and experimental value of the $\mathrm{O} 1 \cdots \mathrm{O} 2$ distance close to $2.5 \AA$ might suggest strong $\mathrm{O}-\mathrm{H} \cdots \mathrm{O}$ intramolecular bond. Estimation of the strength of intramolecular
H-bonds for systems in a crystal is not trivial. One of the simplest methods for determining $\mathrm{H}$-bond strength in vacuum is the calculation of the difference in energy between closed $(\mathrm{X}-\mathrm{H} \cdots \mathrm{Y})$ and open configuration. However, this approach cannot be applied for a system in a crystal. Therefore, for estimating this intramolecular H-bond, we used the very simple relation proposed by Musin and Marian: ${ }^{52}$

$$
E_{\mathrm{HB}}=\left(5.554 \times 10^{5}\right) \exp (-4.12 R),
$$

where $R$ is the $\mathrm{O} \cdots \mathrm{O}$ distance. Using the value of $2.5 \AA$, which is close to the experimental and average values from CPMD simulations, the estimated $\mathrm{H}$-bond strength is equal to $-18.7 \mathrm{kcal} \mathrm{mol}^{-1}$. The strength of $\mathrm{H}$-bond in a crystal estimated by us is in good agreement with the value of $-16.3 \mathrm{kcal} \mathrm{mol}^{-1}$ obtained in vacuum on the basis of DFT calculations by proposed by Schiøtt and coworkers. ${ }^{30}$ It implies that this H-bond is strong. in the group of intramolecular hydrogen bonds.

\subsection{IR spectra}

For crystal (I) and (II), selected characteristics of vibrational frequencies from CPMD, together with harmonic frequencies from static calculations and available experimental data, are presented in Table 2. Fig. 10 presents the CPMD infrared spectrum for both the examined crystals $\mathrm{BA}$ and $\mathrm{D}_{2} \mathrm{BA}$ with experimental spectra for BA crystal. ${ }^{53,54}$ For further comparative vibrational analysis, we also compared the simulated and experimental spectra for BA crystal and its deuterated analogue, as illustrated in Fig. 11. The assignments of the calculated frequencies are based on the experimental $\mathrm{IR}^{53}$ spectra for benzoylacetone and its deuterated analogue. As we know, infrared 

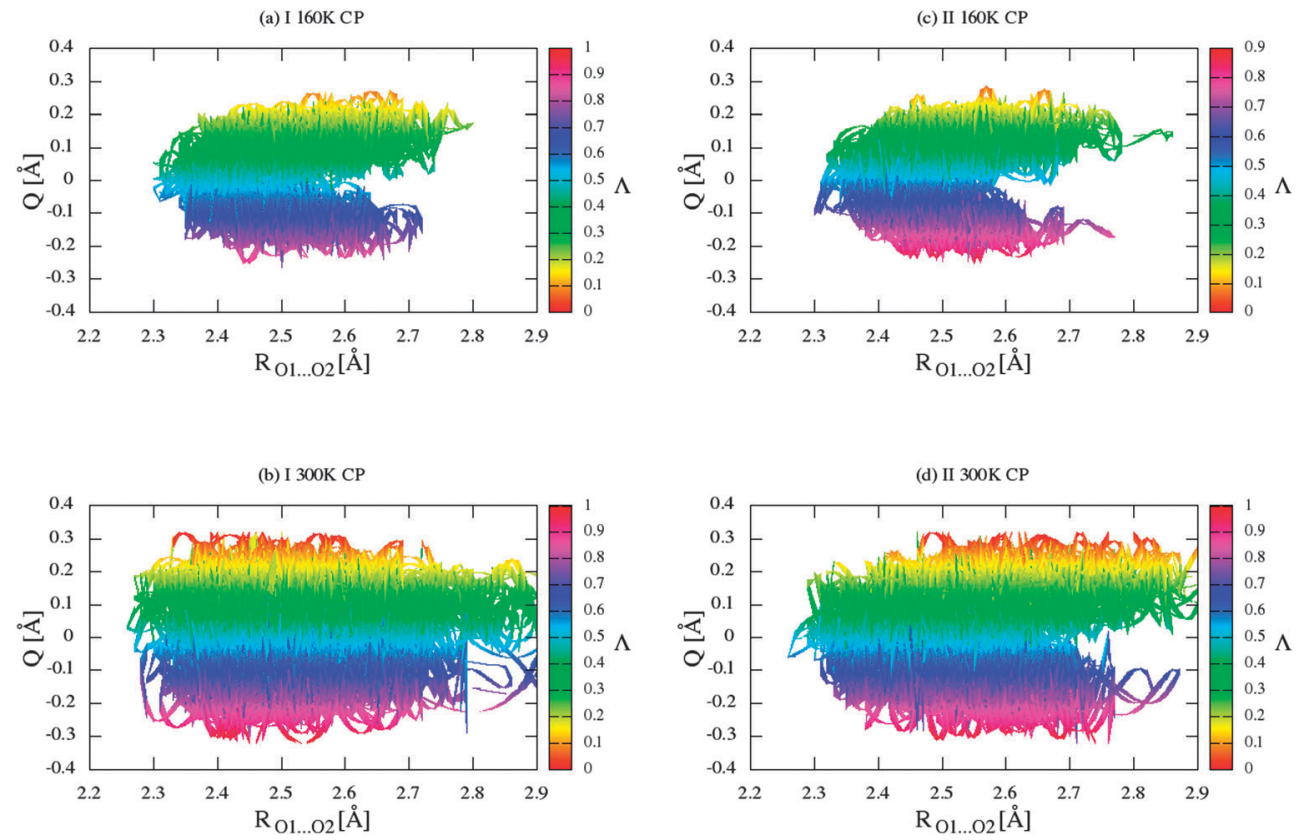

Fig. 9 Two-dimensional $\pi$-delocalization index ( $\Lambda$ ) landscape of $R_{\mathrm{O} 1 \ldots \mathrm{O} 2}$ distances and delocalization parameter (Q) for crystal (I) for (a) CPMD simulation at $160 \mathrm{~K}$, (b) CPMD simulation at $300 \mathrm{~K}$, and for crystal (II) for (c) CPMD simulation at $160 \mathrm{~K}$, (d) CPMD simulation at $300 \mathrm{~K}$.

spectroscopy is a very useful experimental method for studying the strength of the hydrogen bond and it is also very important because it confirms that the results of molecular dynamics simulation are correct. In the context of this paper, the analysis of the vibration frequency of - $\mathrm{OH}$ groups appears to be the most important. The characteristics of $-\mathrm{OH}$ stretching vibration in the enol form of the $\beta$-diketones appears as a weak and a very broad band in the $3300-2000 \mathrm{~cm}^{-1}$ region. ${ }^{55-58}$ The intensity and broadness of this band are dependent on the strength of the intramolecular hydrogen bond. ${ }^{53}$ We have observed that the stretching vibrations - $\mathrm{OH} /-\mathrm{OD}$ are shifted in comparison to the $-\mathrm{OH} /-\mathrm{OD}$ frequencies of bonds not involved in $\mathrm{H}$-bond to lower frequencies of about $2217 / 1681 \mathrm{~cm}^{-1}$ and $2514 / 1922 \mathrm{~cm}^{-1}$ for crystals (I) and (II), respectively, in both the calculation methods. The calculated stretching vibrations $-\mathrm{OH} /-\mathrm{OD}$ are in good agreement with experimental results $\left(2650 / 1960 \mathrm{~cm}^{-1}\right)$ but

Table 2 Comparison of the experimental and calculated selected vibrational frequencies in $\left(\mathrm{cm}^{-1}\right)$ for the crystals (I) and (II)

\begin{tabular}{|c|c|c|c|}
\hline Assignment frequencies & PBE/pob_TZVP_2012 (I)/(II) & CPMD/PBE/80 Ry (I)/(II) & Exptl. $^{53}$ (I)/(II) \\
\hline$\nu \mathrm{CH}_{\text {ring assym. }}$ & $3153 / 3152$ & $3023 / 3015$ & $3070^{b} / 3090^{b}$ \\
\hline$\nu \mathrm{CH}$ & $3114 / 3114$ & $2956 / 2937$ & $3030^{b} / 3030^{b}$ \\
\hline$\nu \mathrm{CH}_{3 \text { assum. }}$ & $3072 / 3071$ & $2916 / 2895$ & $3000^{b} / 3000^{b}$ \\
\hline$\nu \mathrm{CH}_{3 \text { symm. }}$ & $2986 / 2988$ & $2892 / 2856$ & $2920^{b} / 2920^{b}$ \\
\hline$\delta \mathrm{OH}+\nu \mathrm{C}=\mathrm{O}-\mathrm{C}=\mathrm{C} / \delta \mathrm{OD}+\nu \mathrm{C}=\mathrm{O}-\mathrm{C}=\mathrm{C}$ & $1605 / 1540$ & $1609 / 1511$ & $1600^{a} 1605^{b} / 1516^{b}$ \\
\hline$\nu \mathrm{C}=\mathrm{C}+\delta \mathrm{OH} / \nu \mathrm{C}=\mathrm{C}+\delta \mathrm{OD}$ & $1597 / 1461$ & $1579 / 993$ & $1570^{a} 1572^{b} / 1098^{b}$ \\
\hline$\nu \mathrm{C}=\mathrm{C}+\delta \mathrm{OH} / \nu \mathrm{C}=\mathrm{C}+\delta \mathrm{OD}$ & $1572 / 1433$ & $1552 / 969$ & $1555^{a} 1554^{b} / 1098^{b}$ \\
\hline$\delta \mathrm{CH}_{3}+\delta \mathrm{CH}+\nu \mathrm{C}-\mathrm{C}=\mathrm{C}-\mathrm{O}$ & $1497 / 1415$ & $1465 / 1320$ & $1458^{a} 1458^{b} / 1362^{b}$ \\
\hline$\delta \mathrm{CH}_{3}$ & $1443 / 1433$ & $1423 / 1407$ & $1430^{b} / 1430^{b}$ \\
\hline$\nu \mathrm{C}-\mathrm{O}+\delta \mathrm{OH}+\delta \mathrm{CH}_{3} / \nu \mathrm{C}-\mathrm{O}+\delta \mathrm{OD}+\delta \mathrm{CH}_{3}$ & $1408 / 1343$ & $1412 / 1073$ & $1430^{b} / 1135^{b}$ \\
\hline$\nu \mathrm{C}-\mathrm{C}=\mathrm{C}+\delta \mathrm{OH} / \nu \mathrm{C}-\mathrm{C}=\mathrm{C}+\delta \mathrm{OD}$ & $1299 / 1072$ & $1284 / 991$ & $1280^{a} 1272^{b} / 1070^{b}$ \\
\hline$\gamma \mathrm{C}-\mathrm{CH}_{3}$ & $556 / 549$ & $561 / 550$ & $588^{a} 588^{b} /-$ \\
\hline$\nu \mathrm{O} \cdots \mathrm{O}+\delta \mathrm{C}-\mathrm{CH}_{3}$ & $410 / 395$ & $345 / 279$ & $396^{a} 396^{b} / 384^{b}$ \\
\hline$\gamma \mathrm{C}-\mathrm{CH}_{3}$ & $152 / 150$ & $161 / 162$ & $153^{a} / 143^{b}$ \\
\hline$\tau \mathrm{CH}_{3}$ & $147 / 144$ & $136 / 140$ & $138^{a} / 143^{b}$ \\
\hline
\end{tabular}

Experimental data from ref. 53. ${ }^{a}$ IR of BA in solid state. ${ }^{b}$ IR of BA in $\mathrm{CCl}_{4}$ solution. 


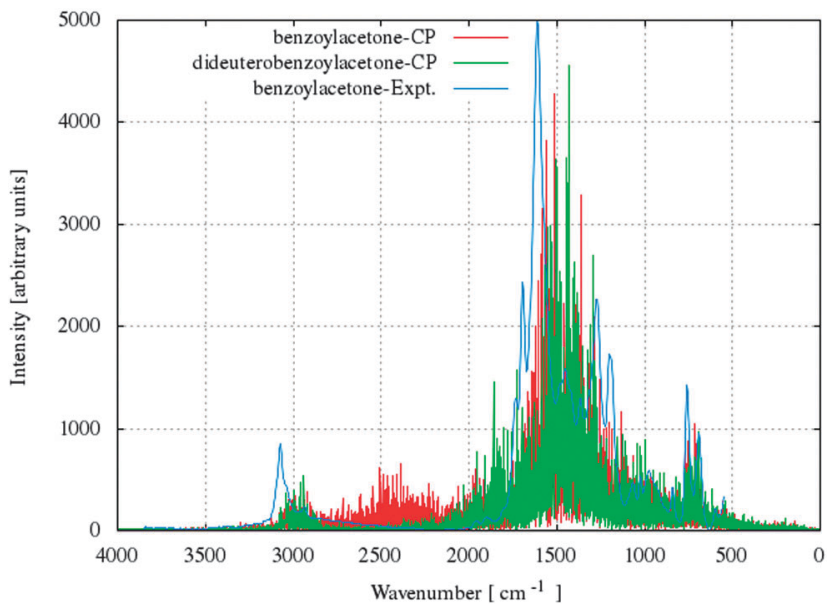

Fig. 10 Comparison of the experimental (blue line) $)^{53,54}$ and simulated IR spectra for benzoylacetone (red line) and dideuterobenzoylacetone (green line).

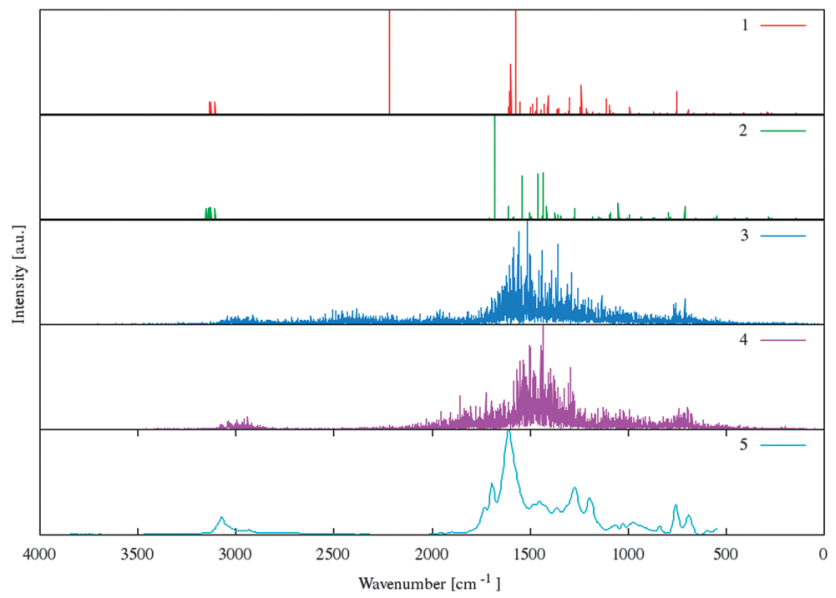

Fig. 11 Comparison of the experimental and simulated IR spectra for benzoylacetone in the solid state. The numbers of spectra were assigned as follows: (1) benzoylacetone and (2) dideuterobenzoylacetone in the solid state from the DFT (PBE) harmonic calculation with London-type empirical correction for dispersion interactions, (3) benzoylacetone and (4) dideuterobenzoylacetone in the solid state from CP molecular dynamics simulation at $300 \mathrm{~K}$ and number (5) experimental IR absorbance spectrum $^{53,54}$ for the benzoylacetone in the solid.

it appears that the CP molecular dynamics method reproduces the frequencies of vibrations better than static methods in harmonic approximation in every case. As compared with the experiment, most of the frequencies from CPMD methods are slightly shifted toward a lower frequency; however, no clear tendency can be observed because some frequencies are a slightly higher. As expected, we observed very large red shift effects of -OH stretching vibrations in these molecular systems. This phenomenon is typical for the incidence of enol-enol resonance structure with the strong intramolecular hydrogen bond.

A very important parameter related with the IR spectra of $\mathrm{H}$-bonded systems is the isotope effect defined by the isotopic ratio (ISR) $\nu \mathrm{OH} / \nu \mathrm{OD}$. Because of the anharmonicity in a majority of H-bonded systems, the ISR value is different from $\sqrt{ } 2$. It has been shown that in the case of $\mathrm{O}-\mathrm{H} \cdots \mathrm{OH}$-bonds, the maximum value of ISR does not exceed 1.5. ${ }^{59}$ The calculated ISR values equal 1.32, 1.31, 1.35 from the static calculations, CPMD simulations and experiment, respectively. These values also indicate a very strong hydrogen bond and high mobility of proton in the hydrogen bridge. We observed a good agreement of the experimental data $\left(3110 / 2313 \mathrm{~cm}^{-1}\right)$ with the calculated $(3186 / 2361$ $\mathrm{cm}^{-1}$ and $3107 / 2336 \mathrm{~cm}^{-1}$ ) values for -CH/-CD stretching vibration frequency. In this case, we can also see a very large isotopic effect for these vibrations. The $\mathrm{O} \cdots \mathrm{O}$ stretching mode for BA in the experiment appears at about $396 / 384 \mathrm{~cm}^{-1}$. According to our static and CP calculations, these modes are located at about $410 / 395 \mathrm{~cm}^{-1}$ and $345 / 279 \mathrm{~cm}^{-1}$. The $\nu \mathrm{O} \cdots \mathrm{O}$ mode is coupled with $\delta \mathrm{C}-\mathrm{CH}_{3}$ and the position of this band relates to other $\beta$-diketones, which also suggests the existence of very strong $\mathrm{HB}$.

\section{Conclusion}

We have presented the results of theoretical studies on the intramolecular hydrogen bonds in 1-phenyl-1,3-butadione and its deuterated analogue 1-deuteroxy-2-deutero-1-phenylbut-1-en3 -one in the solid state using static as well as ab initio molecular dynamics methods. In our study of both the crystals, we found evidence for the existence of strong $\pi$-delocalized structure (enol-enol forms) with the location of the enol hydrogen in a very flat slightly asymmetric (almost symmetric) single minimum potential, which is in accordance with neutron diffraction studies performed by Madsen ${ }^{24,25}$ and co-workers. The analysis of average distances in the geometric structure of four bonds in the keto-enol parts of the molecule indicated that the equivalence of the bond lengths may be attributed to delocalization over a conjugated $\pi$-bonded system in the keto-enol group. We also calculated the $\pi$-delocalization index (which is equal to 0.445) for the both crystals taking as the basis for calculating the average bond lengths from CPMD simulation. In addition, the calculated correlation between the $Q$ and the $\Lambda$ parameters and the length of the hydrogen/deuter bridge throughout the simulation shows that the system is characterized by the type of strong $\pi$-delocalized structure (enol-enol forms) with slightly more contribution from the $\pi$-localized enol-keto (EK) form than $\pi$-localized keto-enol (KE) form. In our opinion, all the arguments presented above (a relatively short hydrogen bridge, non-ideal symmetrical position of the proton, the shape of the potential function of proton, the correlation between the $Q$ and $\Lambda$ parameters and very big red shift effects of $-\mathrm{OH}$ stretching vibrations) indicate that the hydrogen bonds in the benzoylacetone crystals have properties characteristic of the type of bonding model resonance-assisted hydrogen bonds without the existing equilibrium of the two tautomers.

\section{Acknowledgements}

This paper is dedicated to the memory of my wonderful Mother, who recently passed away. The authors would like to 
gratefully acknowledge the Academic Computer Centre in Gdansk (CI TASK) for the use of the Galera-ACTION Cluster and the Wroclaw Centre for Networking and Supercomputing (WCSS) for the use of the Supernova Cluster. Dr Przemysław Dopieralski is acknowledged for helpful discussion as well as help with preparing the AWK's scripts.

\section{References}

1 T. Steiner, Angew. Chem., Int. Ed., 2002, 41, 48.

2 G. A. Jeffrey, An Introduction of Hydrogen Bonding, Oxford University Press, New York, USA, 1997.

3 W. W. Cleland and M. M. Kreevoy, Science, 1994, 264, 1887.

4 A. Warshel, A. Papazyan and P. A. Kollman, Science, 1995, 269, 102.

5 G. R. Desiraju and T. Steiner, The Weak Hydrogen Bond: In Structural Chemistry and Biology.(International Union of Crystallography Monographs on Crystallography; no. 23), Oxford University Press, USA, 1997.

6 P. Durlak, K. Mierzwicki and Z. Latajka, J. Phys. Chem. B, 2013, 117, 5430.

7 P. Sanz, O. Mó, M. Yáñez and J. Elguero, J. Phys. Chem. A, 2007, 111, 3585.

8 R. N. Singh, A. Kumar, R. K. Tiwari, P. Rawat, V. Baboo and D. Verma, Spectrochim. Acta, Part A, 2012, 92, 295.

9 H. Karabiyık, R. Sevinçek, H. Petek and M. Aygün, J. Mol. Model., 2012, 17, 1295.

10 S. W. Rick and S. J. Stuart, Potentials and Algorithms for Incorporating Polarizability in Computer Simulations, in Reviews in Computational Chemistry, ed. K. B. Lipkowitz, T. R. Cundari, V. J. Gillet and D. B. Boyd, Wiley-VCH, Hoboken, New Jersey, 2002, vol. 18, pp. 89-146.

11 P. Gilli, V. Bertolasi, L. Pretto, L. Antonov and G. Gilli, J. Am. Chem. Soc., 2005, 127, 4943.

12 P. Gilli, V. Bertolasi, L. Pretto, V. Ferretti and G. Gilli, J. Am. Chem. Soc., 2004, 126, 3845.

13 P. Gilli, V. Bertolasi, V. Ferretti and G. Gilli, J. Am. Chem. Soc., 1994, 116, 909.

14 V. Bertolasi, P. Gilli, V. Ferretti and G. Gilli, J. Am. Chem. Soc., 1991, 113, 4917.

15 G. Gilli, F. Bellucci, V. Ferretti and V. Bertolasi, J. Am. Chem. Soc., 1989, 111, 1023.

16 G. Gilli and P. Gilli, The Nature of the Hydrogen Bond: Outline of a Comprehensive Hydrogen Bond Theory (International Union of Crystallography Monographs on Crystallography; no. 23), Oxford University Press, USA, 2009.

17 N. V. Belova, V. V. Sliznev, H. Oberhammer and G. V. Girichev, J. Mol. Struct., 2010, 978, 282.

18 F. Gomez-Garibay, J. S. Calderon, L. Quijano, O. Tellez, M. Soccoro-Olivares and T. Rios, Phytochemistry, 2001, 46, 1285.

19 F. Wetz, C. Routaboul, D. Lavabre, J. C. Garrigues, I. RicoLatters, I. Pernet and A. Denis, Photochem. Photobiol., 2004, 80, 316.

20 V. Bertolasi, V. Ferretti, P. Gilli, X. Yao and Ch.-J. Li, New J. Chem., 2008, 32, 694.
21 C. M. Silvernail, G. Yap, R. D. Sommer, A. L. Rheingold, V. W. Day and J. A. Belot, Polyhedron, 2001, 20, 3113.

22 J. A. Belot, J. Clark, J. A. Cowan, G. S. Harbison, A. I. Kolesnikov, Y.-S. Kye, A. J. Schultz, C. Silvernail and X. Zhao, J. Phys. Chem. B, 2004, 108, 6922.

23 N. V. Belova, G. V. Girichev, H. Oberhammer, T. N. Hoang and S. A. Shlykov, J. Phys. Chem. A, 2012, 116, 3428.

24 G. K. H. Madsen, B. B. Iversen, F. K. Larsen, M. Kapon, G. M. Reisner and F. H. Herbstein, J. Am. Chem. Soc., 1998, 120, 10040.

25 G. K. H. Madsen, G. J. McIntyre, B. Schiøtt and F. K. Larsen, Chem. - Eur. J., 2007, 13, 5539.

26 F. H. Herbstein, B. B. Iversen, M. Kapon, F. K. Larsen, G. K. H. Madsen and G. M. Reisner, Acta Crystallogr., Sect. B: Struct. Sci., 1999, 55, 767.

27 S. I. Chan, L. Lin, D. Clutter and P. Dea, Proc. Natl. Acad. Sci. U. S. A., 1970, 65, 816.

28 E. V. Borisov, E. V. Skorodumov, V. M. Pachevskaya and P. E. Hansen, Magn. Reson. Chem., 2005, 43, 992.

29 J. W. Bunting, J. P. Kanter, R. Nelander and Z. Wu, Can. J. Chem., 1995, 73, 1305.

30 B. Schiøtt, B. B. Iversen, G. K. H. Madsen and T. C. Bruice, J. Am. Chem. Soc., 1998, 120, 12117.

31 D. Marx, Advanced Car-Parrinello Techniques: Path Integrals and Nonadiabaticity in Condensed Matter Simulations, in Computer Simulations in Condensed Matter Systems: From Materials to Chemical Biology Volume 2, Lect. Notes Phys., ed. M. Ferrario, G. Ciccotti and K. Binder, Springer, Berlin, 2006, vol. 704, pp. 507-539.

32 M. E. Tuckerman, Path Integration via Molecular Dynamics, in Quantum Simulation of Complex Many-Body Systems: From Theory to Algorithms, ed. J. Grotendorst, D. Marx, A. Muramatsu, John von Neumann Institiute for Computing (NIC), Juelich, Germany, 2002, vol. 10, pp. 269-298.

33 S. J. Grimme, J. Comput. Chem., 2006, 27, 1787.

34 R. Dovesi, V. R. Saunders, C. Roetti, R. Orlando, C. M. Zicovich-Wilson, F. Pascale, B. Civalleri, K. Doll, N. M. Harrison, I. J. Bush, Ph. D'Arco and M. Llunell, CRYSTAL09 User's Manual, University of Torino, Torino, 2009.

35 R. Dovesi, R. Orlando, B. Civalleri, C. Roetti, V. R. Saunders and C. M. Zicovich-Wilson, Z. Kristallogr., 2005, 220, 571.

36 J. P. Perdew, K. Burke and M. Ernzerhof, Phys. Rev. Lett., 1996, 77, 3865.

37 H. J. Monkhorst and J. D. Pack, Phys. Rev. B: Solid State, 1976, 13, 5188.

38 M. F. Peintinger, D. Vilela Oliveira and T. Bredow, J. Comput. Chem., 2013, 34, 451.

39 CPMD, version 3.15.3; Copyright IBM Corp 1990-2008, Copyright MPI für Festkörperforschung Stuttgart 19972001; http://www.cpmd.org.

40 G. J. Martyna, M. L. Klein and M. Tuckerman, J. Chem. Phys., 1992, 97, 2635.

41 N. Troullier and J. L. Martins, Phys. Rev. B: Condens. Matter Mater. Phys., 1991, 43, 1993.

42 W. Humphrey, A. Dalke and K. Schulten, J. Mol. Graphics, 1996, 14, 33. 
43 T. Williams and C. Kelley, Gnuplot 4.5 (patchlevel 5), 2014, http://gnuplot.info.

44 A. Kohlmeyer and H. Forbert, traj2xyz.pl, version 1.4, 2004. 45 H. Forbert and A. Kohlmeyer, Fourier, version 2, 2002-2005. 46 P. Durlak and Z. Latajka, J. Mol. Model., 2011, 17, 2159.

47 P. Durlak and Z. Latajka, J. Chem. Theory Comput., 2013, 9, 65.

48 C. A. Morrison, M. M. Siddick, P. J. Capm and C. C. Wilson, J. Am. Chem. Soc., 2005, 127, 4042.

49 S. Pantano, F. Alber and P. J. Carloni, THEOCHEM, 2000, 530, 177.

50 C. C. Wilson, N. Shankland and A. J. Florence, Chem. Phys. Lett., 1996, 253, 103.

51 W. W. Cleland, Biochemistry, 1992, 31, 317.

52 R. N. Musin and Y. H. Marian, J. Phys. Org. Chem., 2006, 19, 425.

53 S. F. Tayyari, J. S. Emampour, M. Vakili, A. R. Nekoei, H. Eshghi, S. Salemi and M. Hassanpour, J. Mol. Struct., 2006, 794, 204.
54 NIST/EPA Gas-Phase Infrared Database JCAMP Format. http:// webbook.nist.gov/cgi/cbook.cgi?ID=C93914\&Mask=80\#Refs.

55 S. F. Tayyari and F. Milani-Nejad, Spectrochim. Acta, Part A, 2000, 56, 2679.

56 R. R. Lozada-Garcia, J. Ceponkus, W. Chin, M. Chevalier and C. Crépin, Chem. Phys. Lett., 2011, 504, 142.

57 Z. Yoshida, H. Ogoshi and T. Tokumitsu, Tetrahedron, 1970, 26, 5691.

58 S. F. Tayyari, T. Zeegers-Huyskens and J. L. Wood, Spectrochim. Acta, Part A, 1979, 35, 1265.

59 Z. Latajka and L. Sobczyk, The Potential Energy Shape for the Proton Motion In Protonated Naphthalene Proton Sponges (DMAN-s) and its Manifestations, in Practical Aspects of Computational Chemistry. Methods, Concepts and Applications, ed. J. Leszczynski and M. K. Shukla, Springer, Heidelberg, Dordrecht, London, New York, 2010, pp. 371-386. 